\title{
New Sustainable Fibres and their application in Textiles: A Review
}

\author{
Oinam Roselyn Devi
}

Research Scholar, Department of Apparel and Textile Science, Punjab Agricultural University, Punjab, India

To Cite this Article

Oinam Roselyn Devi, "New Sustainable Fibres and their application in Textiles: A Review", International Journal for Modern Trends in Science and Technology, 6(9S): 136-141, 2020.

Article Info

Received on 25-August-2020, Revised on 08-September-2020, Accepted on 12-September-2020, Published on 18-September-2020.

\section{ABSTRACT}

Presently, sustainability became a key mantra in all the industries across the world, especially the textile sector as it is one of the largest industries in the world. In textile science, natural fibres have a big role in a sustainable environment-friendly future and became a significant topic to exploit a new natural resource which is green and environment-friendly. Considering this, fibres from various sources were explored by many researchers for its potentialities in improving the quality of life around the world. Aloe vera, banana, sisal, hemp, jute, bamboo, milk fibre, corn, soya, groundnut shell, arecanut, coffee bean waste, lyocell and eucalyptus were few among them. Each year, more synthetic fibres and high energy-consuming products are being replaced by natural-fiber-based products. Additionally, natural fibres have been used not only for clothing but also for technical applications such as composite materials, building materials, filtration and insulation materials. The reason for this trend is not only due to increase environmental awareness but also because of its excellent properties, such as lightweight, strength, low costs and simple sourcing. Meanwhile,waste utilization became one of the important and challengeable jobs around the world. The Textile industry has obtained many fibres from bioresource waste as an important step toward sustainable development. As for example, Pinafibre is a minor fibre obtained from waste pineapple leaves. The study attempted to review some of the selected new sustainable fibres from waste materials and their application in textiles.

KEYWORDS: Sustainability, Environment-friendly, Sustainable fibres, Waste materials

\section{INTRODUCTION}

Since prehistoric age, the mankind utilized the natural fibres significantly earlier than metals, alloys, and ceramic. As for example, flax was harvested in Mesopotamia, cotton was cultivated in the Indus River region, silk was obtained from domesticated silkworm in North Chine, wool was originated in West Asia, and linen was used in Ancient Egypt [1].

The natural textile fibres have been significant due to its widespread in nature and technical suitability for many centuries. However, due to difficulties in obtaining natural fibres such as cost, desire to obtain products with higher qualities, fashion, and inability to meet the demands, textile science has explored new fibres which can substitute the natural fibres[2]. As global demand for textile increased, synthetic fibre started to produce by the twentieth century. Cellulose acetate fibre, which is the first synthetic fibre, was produced and later nylon 6, 6, nylon 6, polyester, and polyacrylic fiber were introduced. Although these synthetic fibres are less expensive than the natural fibres, and easier to produce in large quantities, but, it caused harmful hazards to the eco-system, health of the wearer with disposal issues as well [3].

The term "sustainability" means establishing those principles and practices which can help to maintain the equilibrium of nature, in other words, 
producing materials with less impact on the environment [4]. Being aware of environmental issues, today, consumer have started looking for "Green Products" or eco- friendly products everywhere. In terms of textile products, the purchasing decisions of consumers were previously based upon comfort, style, aesthetic appeal, etc., but now more on eco-friendliness of products. Many clothing companies have started providing clothes made from eco-friendly fabrics, and the demands for these green products are increasing. Samatoa, H\&M, Lenzing, LoroPianaetc. are some of companies which produced ecofriendly textile fabrics.

In textile science, natural fibres are known as sustainable raw materials. In December 2006, the United Nations General Assembly declared 2009 as the "International Year of Natural Fibres - IYNF", a year-long initiative focused on raising global awareness about natural fibers with a specific focus on increasing market demand to ensure the long-term sustainability for farmers who rely heavily on their production [5].

Currently, natural fibres have been used not only for clothing but also for technical applications such as composite materials [6], building materials [7], filtration [8] and insulation materials [9] because of low price, sustainability, lightness, high strength, high insulation properties, andsimple sourcing. The increase in awareness of the damage caused by synthetic materials on the environment has led to the development of eco-friendly materials.

Considering this, fibres from various natural sources were explored by many researchers for its potentialities in improving the quality of life around the world. Aloe vera, banana, sisal, hemp, jute, bamboo, milk fibre, corn, soya, groundnut shell, arecanut, coffee bean waste, lyocell and eucalyptus are few among them [10].

Meanwhile, waste utilization became one of the important and challengeable jobs around the world. The Textile industry has obtained many fibres from bioresource waste as an important step toward sustainable development. As for example, Pinafibre is minor fibre obtained from waste pineapple leaves. Therefore, the study attempted to review some of the selected new sustainable fibres from waste materials and their application in Textiles.

\section{NEW SUSTAINABLE FIBERS AND THEIR APPLICATION IN TEXTILES}

\section{A. Lotus silk fibre}

The lotus (Nelumbonucifera) belongs to the family Nelumbonaceae, also known as Indian lotus, sacred lotus, bean of India, Egyptian bean or simply lotus [11]. It is bloom in entire India, Asia and Queensland, Australia. It is the national flower of India and Vietnam. It is considered as a spiritual plant and the motif of lotus flower is a very popular design in textiles [12]. Among various religions, Hinduism and Buddhism have a strong religious connection with lotus plant. In ancient days, Cambodian monks have worn natural dyed lotus fabric as a symbol of peaceful living, purity and divinity [12].

Currently, a considerable amount of lotus stems are left in the pond to be wasted after the blossom season or the harvest of lotus roots. These residues consist of abundant natural cellulose resources which can be used in the textile, paper, medical and construction industries [13]. Extracting fibres from the lotus stems have been in practice since 1910. Later during the 90's designers of Japan setup workshops to create a foreign market for their fabric. But due to low demand in Japan, the lotus fibre fabric remained a rare and handmade textile. In the textile sector, lotus fibres are being used to manufacture luxury garments.

Extraction of lotus stem fibre is done by hand, but due to the low efficiency of manual preparation limits large-scale use of lotus fibres. Developing convenient and efficient methods for preparing lotus fibres has attracted the attention of researchers more and more. The entire manufacturing process is time- consuming and completely handmade, resulting to limit in the quantity of the fabric produced. Stems of the lotus plants are collected, cut, snapped, and twisted to expose their fibres. These are thin and white filaments around 20-30 in number, which are rolled into a single thread. Fibres extracted from the stem are spun into yarn. The extracted fibres are placed in the skeins on a bamboo spinning frame preparing them for warping.Yarns are made by placing the fibers on a bamboo spinning frame and transferring the thread into winders for warping.

A study stated that microwave irradiation is a convenient and efficient method for producing lotus fibres.In microwave technology, fresh lotus 
stems were washed and dried at room temperature. Dried lotus stems were cut and placed into $\mathrm{NaOH}$ solution and later treated under microwave irradiation. The lotus stems were then washed in deionized water to neutral $\mathrm{pH}$. After that, the fibreswere separated from the lotus stems and named as raw lotus fibres.Preparing fibres with hydrogen peroxide under microwave irradiation has become more and more popular because it is an environment-friendly and efficient method for obtaining cellulose resources[13].

These stem fibres have also been widely used as porous and composite materials [14-15]. Garment produced from lotus fibre has unique properties such as good breathable, wrinkle-free property, UV resistance property, good moisture absorption, air permeability, soft and comfort properties, bio-degradable, eco-friendly, organic and gave silk-linen combination feel [16]. Nomark lotus shirt is a popular brand that sells Men's shirt made from lotus fibre. It is light in weight, requires less washing, durable, breathable, smoothening and also believed in having healing properties for mild body ailments. Kyar hi makes scarf for domestic market and exports. LoroPiana, an Italian luxury brand that designed and showcased a 100\% lotus fibre garment in the Parisian fair. Samatoa, is also an another popular brand that makes Lotus textiles. In 2012 they sent a handcrafted lotus sarong to UNESCO, and received the SOE- Seal of Excellence [17]. Recently, Samatoa produced 3-layers sustainable fabric mask from lotus fibre.

\section{B. Water hyacinth stems fibre}

Water hyacinth (Eichhorniacrassipes) is a free-floating aquatic plant and recognized as one of the most top 10 worst weeds in the world. It is grown rapidly without any need for sowing, weeding and fertilizing, when not control; it covers the water sources and creates a serious hazard to biodiversity. In India, water hyacinth is traditionally used for manufacturing paper (under cottage industry), baskets, and matting and animal fodder. It is also used as vermicompost in some parts of the country [18]. It has medicinal value, and involved for the treatment of toxicity in the body, curing infections or wounds. Also, it has the potential to clean up various contaminated waters from dairies, tanneries, textile, sugar factories, pulp and paper industries, palm oil mills and distilleries [19].
In fact, water hyacinth has great potential in textile fields as well as it is rich in cellulose content. Water hyacinth fibre was extracted from the stems (stalks) of the water hyacinth plant by different extraction methods namely mechanical, chemical, boiling and natural alkali extraction. The fibre length and diameter of water hyacinth were 30-50 $\mathrm{cm}$ and $50 \mu$ mapproximately.The stalk of water hyacinth wasfound to be an alternative source for textile material, according to the Department of Science and Technology, Philippine Textile Research Institute (PTRI). Researchers at PTRI have produced the clothing using the water hyacinth fibres as raw material [20]. Also, Department of Textiles and Garments, Faculty of Home Economics Technology at RMUTT have also developed natural fibres from Water Hyacinth to make creative textile products. Compared to linen and hempfibres, the properties of the Water Hyacinth fibers make it lightweight and not hot or stuffy when worn as clothing.

One study reported that the water hyacinth stem fibre can be used to make rope. The stalk from the plant is shredded lengthways to expose the fibres and then left to dry for several days. The rope making process is similar to that of jute rope. The finished rope is treated with sodium meta-bisulphite to prevent it from rotting. In Bangladesh, the rope is used by the local furniture manufacturers who wound the rope around a cane frame to produce an elegant finished product [21]. Needle punched nonwoven insulating fabric was developed by using blended water hyacinth and Sansevieriastuckyifibres [22]. Besides, woven water hyacinth mat can be utilized for erosion control in field applications because the moisture retained in woven water hyacinth was high thus it can help the growth of vegetation [23]. Water hyacinths (Eichorniacrassipes) could also be made into clothes for casual wear, cocktails, and long gowns.Blends of polyester/water hyacinth fibres are ideal for home textiles such as curtains, upholstery, table runners, napkins, bed cover, pillow case, and other items found at home. Today, many water hyacinth fibre made products namely, yoga mat and table runner are commercially available in market.

\section{A. Luffafibre}

Luffacylindrica is a peculiar vegetable belongs to family cucurbitacea, commonly known as vegetable sponge, sponge-gourd, wash sponge, loofah gourd or dishcloth gourd. It is a climbing vegetable crop 
grown in sub-tropical regions that produce fruits containing fibrous vascular system [24]. The matured fruit develop as sponge-like structure. The unripe fruits are generally harvested at an early stage as a vegetable source, whereas the fully ripened fruit is non-edible and very fibrous. Luffafibres are achieved from matured dried fruit. A study has reported luffafibrecomprised of cellulose, hemicelluloses and lignin in an approximate ratio of 6:3:1 [25]. However, the chemical compositions depend on several factors such as plant origin, weather conditions, and soil nature.

Traditionally, these dried mature fruit fibres are generally used as a scratchy scrubber for skin care, that removes skin cell (dead) and to normalize the blood flow of the skin [26]. Some of the attractive properties are high degree of porosity, high water absorption capacity, precise pore volume, non-toxic and biodegradability. Therefore, it has wide applications in various fields such as material science, medical science, biotechnology, bioprocessing engineering, pharmaceutical industry etc.

It is also used for the manufacture of hats, insoles for shoes, car filters, table mats, pot-holders, doormats, flip-flops and scarfs [27]. Moreover, another study also reported that Luffacylindricafibres showed its potential to remove methylene blue dye from aqueous solutions as green adsorbent [28]. Recently, non-woven Luffa/Polyester and Jute/Polyester reinforced composite materials were developed and found that Luffa/Polyester reinforced composite has better impact strength, flexural strength, tensile strength, compression strength than Jute/Polyester reinforced composite materials [29]. In addition, these sponge fibres are also used in medical textile as well. For example, silver incorporation into the micro spongy structure of Luffacylindricafibres by using biopolymer chitosan helps in wound healing process due to the presence of metal chelating groups like amine [30-31]. In negative pressure wound therapy,luffa sponge fibre is also used as an interface dressing material.

\section{Orange peel fibre}

Orange fruit belongs to the family Rutaceae, probably originated from regions comprising of Southern China, Northeast India and Myanmar. Orange is well known for most rich sources of vitamin $\mathrm{C}$, it also contains considerable amounts of carotenoids, flavonoids, essentials oils and some minerals [32]. The world production of orange in 2017-18 was around 54.28 million metric tons; most are being used to make value-added products such as jams, marmalades, juices, and squash, all of which result in around 3.8 million ton of orange peel waste per year. Italy alone produced about 700,000 tons of waste materials and by-products from citrus processing units every year [33]. Orange peel contributes $50-65 \%$ of the total weight of the fruits. The discarded orange fruits as well as its waste materials have been utilized as a low cost biosorbent, a substrate for the production of various enzyme and metabolites and further used for the extraction of bioactive components and functional ingredients, and livestock feed, etc. Also, orange peel wastes have also been used as an antimicrobial agent, mosquito repellent, natural colorant, bio-absorbent, perfume retention agents etc. in textile sector[34].

Orange peel fibres are invented by the two young Italian girls, Adriana Santanocito specialized in design and innovative textile and Enrica Arena, an expert in communication and marketing. They collected orange peel waste from the city, washed, cleaned and processed them. The orange peel waste is processed with their patentedtechnology known as 'Pastazzo'that extracts the cellulose from the entire orange peel waste. International brand "H\&M" purchased their patented idea and became the first brand in the world to launch the textiles made from orange peel waste.

The fabric made from orange fibre gave soft touch, smooth, silky and shiny and lustrous appearance. It can weave with other existing yarn like cotton, silk and polyester; have good blending ability with other fibres. And fabrics from 100\% orange peel waste fibres are available in light shades that can be dyed, printed, and even washed like other conventional materials. The fabric was sold at $€ 30-€ 40$ per meter. The fabric has vitamin A, C and $\mathrm{E}$ with natural oils therefore; wearing the textiles made out of orange fibre is like wearing a vitamin cream; it nourishes the skin of the wearer [35]. Therefore, Orange fibre transforms industrial waste of citrus into a sustainable and biodegradable textile which is also a cosmetic and vitamin enriched cream to wear and available for high quality collection.

H\&M brand designer"ChatarinaForseth" made custom-made orange fibre gown and worn by Taiwanese actress and sustainability influencer 
"Chiling Lin" at the 2018 Global Change Award ceremony. The fabric was $50 \%$ Orange Fibre and $50 \%$ organic silk, and the skirt was covered by two layers of recycled tulle.

\section{E. Papaya pseudostemfibre}

The papaya plant (Carica papaya) is widely cultivated in tropical and subtropical regions for its well-known delicious fruits and its wide applications e.g., as a medicinal plant or even as a meat tenderizer [36-38]. In commercial plantations, papaya plants are replaced after three to five years because the production of fruits declines rapidly as it grows older. Old trees grow slower and produce lesser fruits. As a result, the old plant stems are usually discarded [39].

Traditionally, papaya bastfibres were used for floral decoration. To date, no one has paid much attention to usage of carica papaya fibers ( $\mathrm{CPFs}$ ) in various industries. However, with rising the usage of green composites in various automobile parts like a front mask, side skirts, dashboard, door panels, and interior panels so, the demand for the natural fibres are increasing day by day which motivate the researchers to check their fitness to act as a reinforcement in polymer matrix. Currently, CPFs have been used in technical textile (mobitech) and its fiber extraction method is eco-friendly and does not cause any hazard to the environment.

The stem was cut and immersed in water for two weeks to allow the inner layer and outer bark detachment. The inner layer was removed manually and disposed of while the bark was retained for further process. The retained bark was immersed in water for another two weeks for microbial degradation. During the time of microbial degradation, the bark degraded enough to extract CPFs. The fibre from the degraded bark was thoroughly washed with tap water, followed by distilled water for isolating the fibre and other greasy materials [40]. A study found that the biodegradable CPFs can be used as potential reinforcement in the polymer matrix composite structure [40]. An industrial safety helmet was developed by using hybrid natural fibre (papaya stem \& sisal fiber) composite materials [41].

\section{CONCLUSION}

In the present scenario, there has been rapid attention in research and development in the new sustainable fibres due to its better abundant, renewable, cost-effective and eco-friendly features. However, sustainable fibres not only contribute to solve the environmental burden but also are becoming a new trend in the fashion market. In textile science, natural fibres have a big role towards a sustainable environment-friendly future. Considering this, fibres from various sources are explored by many researchers for its potentialities in improving the quality of life around the world. Today, natural fibres have been used not only for clothing but also for technical applications such as composite materials, building materials, filtration and insulation materials. The reason for this trend is not only due to increase environmental awareness but also because of its excellent properties, such as lightweight, strength; they have relatively low costs and simple sourcing. Therefore, textile industry has obtained many fibres from natural sources as an important step toward sustainable development.

\section{REFERENCES}

[1] E.N. Ahmed (2012) From Natural to Synthetic fibers, Textiles types, uses and production methods (Materials science and Technologies) Published by Nova Science Inc, Chapter1, pp 1-152.

[2] S. Eyupoglu (2020) Sustainable Plant-Based Natural Fibers, Sustainability in the Textile and Apparel Industries sourcing natural materials (Springer) chapter 2 pp 27-48.

[3] S. Edwards (2016, August) The Environmental impacts of polyester.

https://www.tortoiseandladygrey.com/2016/08/29/envir onmental-impacts-polyester/

[4] K. Thangavel and G. Duraisamy(2014 May) Environmental Analysis of Textile Value Chain: An Overview. Available from DOI: 10.1007/978-981-287-110-7_6

[5] E.G. Jan (2008) Environmental benefits of natural fibre production and use, Proceedings of the Symposium on Natural Fibres,Van Dam Wageningen University, The Netherlands, pp 3-17.

[6] D. Puglia, J. Biagiotti and J.M. Kenny (2005) A Review on Natural Fibre-Based Composites-Part II Application of Natural Reinforcements in Composite Materials for Automotive Industry. J. Nat.Fibers.1(3):23-65.

[7] O. Onuaguluchi and N. Banthia (2016 April) Plant-based natural fibre reinforced cement composites: A review. Cem. Conc. Compos. 68:96-108.

[8] A. Mautner, Y. Kwaw, K. Weiland, M. Mvubu, A. Botha , M.J. John, A. Mtibe, G. Siqueira and A. Bismarck (2019 July) Natural fibre-nanocellulose composite filters for the removal of heavy metal ions from water. Indus.Crops. Prod. 133:325-332.

[9] A. Korjenic, V. Petranek and J. Hroudova (2011 September) Development and performance evaluation of natural thermal-insulation materials composed of renewable resources. Energy.Build. 43(9):2518-2523.

[10] S. Aishwariya and S. Thamima (2019 October) Sustainable textiles from lotus. Asian .Text. J. 28(10):56-59.

[11] https://en.wikipedia.org/wiki/Nelumbo_nucifera 
[12] M.A. Gardetti and S.S. Muthu. The lotus Flower Fiber and Sustainable luxury, Handbook of Sustainable Luxury Textiles and Fashion Vol I (Springer) pp 3-18.

[13] C. Cheng, R. Guo, J. Lan and J. Jiang (2017 September) Extraction of lotus fibres from lotus stems under microwave irradiation. R. Soc. open sci. Available from:https://doi.org/10.1098/rsos.170747.

[14] M. Wu, H. Shuai, Q. Cheng and L. Jiang (2014 March) Bioinspired green composite lotus fibers. Angewandte. Chemie. Int. Ed. 53(13):3358-3361.

[15] Y. Gong,G.T. Han, Y. M. Zhang, J.F. Zhang, W. Jiang and Y. Pan (2015) Extraction of lotus fibres from lotus stems under microwave irradiation. $R$. Soc. open sci.4(9):170747

[16] R. Pandeya, M.K. Sinhab and A. Dubey (2018 July) Cellulosic fibers from Lotus (Nelumbonucifera) peduncle. $J$. Nat. Fibers. Available from: doi: $10.1080 / 15440478.2018 .1492486$

[17] K. Patil (2018 December) Lotus Fiber: A new facet in textile and fashion. Inter. J. Human. Soc. Sci. Invent. 7(12) :71-75.

[18] S. Punitha, K. Sangeethaand M. Bhuvaneshwari (2015 August) Processing of water hyacinth fiber to improve its absorbency. Inter.J.Advan. Res.3(8):290-294.

[19] R. Keawmanee(2015) "Water Hyacinth - The Green Potential" Master Thesis, Rochester Institute of Technology.

[20] E. Marin, M. Leon, D. Marites, S. Mangalindan and B. Nora (2011) Water Hyacinth (Eichhorniacrassipes) for Yarn manufacture. PTRI Samay Bulletin.

[21] Tanushree, B. Chanana and S. Sethi (2018) Water hyacinth: A wonder weed. Inter. J. Hom. Sci.4(1):291-294.

[22] M. Bhuvaneshwariand K. Sangeetha (2017, August-October) Development of water hyacinth nonwoven fabrics for thermal insulation. i-manager's $J$. Fut. Engineer.Technol.13(1) 22-29.

[23] M.F. Chow, H. Hashrim, S.T. Chong and Y.J. Ng (2019 May) Investigating the effectiveness of Water Hyacinth Fiber Mat for Soil Erosion Control. IOP Conference Series: Materials Science and Engineering. Available from:doi:10.1088/1757-899X/551/1/012008.

[24] M.A. Azeez,O.S. Bello and A.O. Adedeji (2013) Traditional and medicinal uses of Luffacylindrica : A Review. $J$. Med.Plants. Stud. 1(5):102-111.

[25] V. Gianpietro, S. Amaducci and L. Vannini (2000) Multi-use Crops, Programme by DG XII of the European Commission. Department of Agronomy,University Bologna. pp. 82-83.

[26] K. Labeeba, D.D. Ramya and H.B.N. Vedha (2019 April) Comprehensive Review on Potential Applications of Natural LuffaCylindrica Fibers. Phytopharmaceuticalsand Drug Delivery Approaches.pp 2-17. Available from:DOI: 10.29290/PDDA.1.7.2019.2-17.

[27] K.G.Satyanarayana, J.L. Guimaraesand F. Wypych (2007 July) Studies on lignocellulosic fibers of Brazil. Part Isource, production, morphology, properties and applications.Compos. Part A: Appl. Sci. Manuf.38(7):1694-1709.

[28] H. Demir, A. Top, D. Balkose and S. Ulku (2008 May) Dye adsorption behavior of Luffacylindrica fibers. J. Hazard. Mat.153(1-2):389-394.

[29] P. Chandrasekaran, V.R. Babu, S. Ariharasudhan, S. Natarajan and A. Arunraj (2018 December) The development of composites using luffafibre nonwoven for automotive applications. Inter. J. MechanProducEng Res. Develop.8(7) :1609-1616.

[30] R.A.A.Muzzarelli (1973) Natural chelating polymers; alginic acid, chitin and chitosan. Oxford: New York, Pergamon Press.
[31] G. Strobin, M. Kucharska, D. Ciechanska, D. Wawro, W. Stęplewski, J. Jozwicka and S. Sobczak (2006) Biomaterials contain chitosan and fibroin. Polish Chitin Society, Monograph XI, pp 62-68.

[32] A. Topuz, M. Topakci, M. Canakci, I. Akinci and F. Ozdemir (2005 February) Physical and nutritional properties of four orange varieties. J. Food. Eng.66(4):519-523.

[33] United States Department of Agriculture January 2020 Reports. "Citrus: World Markets and Trade". Retrieved from

https://apps.fas.usda.gov/psdonline/circulars/citrus.pdf

[34] O.R. Devi and H. Saini (2020 June) Utilization of orange peel waste in textile industry: A review. Int. J. Chem. Stud. 8(4):5-8.

[35] S. Aishwariya (2020) Textiles from orange peel waste. Scientific Technol Dev. J. 23(2):508-516.

[36] K.L. Krishna, M. Paridhavi and J.A. Patel (2008 January) Review on nutritional, medicinal, and pharmacological properties of Papaya (Carica papaya Linn.). Nat. Prod. Radiance.7 (4):364-373.

[37] J.K. Lalla and S. Ogale (2015) Pharmacognistic evaluation of leaves of Carica papaya Linn. World J. Pharma. Pharma. Sci.4(8):1066-1081.

[38] T. Vij and Y. Prashar (2015 January) A review on medicinal properties of Carica papaya Linn. Asian. Pac. J. Trop. Dis.5(1):1-6.

[39] Papaya Production Guide (2019,February), Agribusiness, https://businessdiary.com.ph/2620/papaya-productionguide/

[40] A. S. Kumaar, A. Senthilkumar, T. Sornakumar, S. S. Saravanakumar and V. Arthanariesewaran (2017, December). Physicochemical properties of new cellulosic fiber extracted from Carica papaya bark. J. Nat. Fibers.DOI: 10.1080/15440478.2017.1410514

[41] L. Narayanan, R.M. Giyahudeen and S. Sathishkumar (2017 June) Design and analysis of industrial safety helmet by using hybrid natural fibre (papaya stem \&sisal fiber) composite materials. Inter. J. Pharma. Technol. 9(2):30100-30109. 